\title{
Analysis of Volatile Compounds in Pears by HS-SPME-GCXGC-TOFMS
}

\author{
Chenchen Wang 1,2, Wenjun Zhang 1,2, Huidong Li 1,2, Jiangsheng Mao 1,2, Changying Guo 1,2, \\ Ruiyan Ding ${ }^{1,2}$, Ying Wang ${ }^{3}$, Liping Fang ${ }^{1,2}$, Zilei Chen ${ }^{1,2,4, *}$ and Guosheng Yang ${ }^{5, *}$ \\ 1 Institution of Quality Standard and Testing Technology for Agro-Product, \\ Shandong Academy of Agricultural Science, Jinan 250100, China; wangchenchen0826@163.com (C.W.); \\ zipingguozhang@163.com (W.Z.); lihuidong8066@163.com (H.L.); maojiangsheng@163.com (J.M.); \\ cyguo808@163.com (C.G.); zengding-1978@163.com (R.D.); lpfang922@163.com (L.F.) \\ 2 Shandong Provincial Key Laboratory of Testing Technology for Food Quality and Security, \\ Jinan 250100, China \\ 3 Department of Bioengineering, Qilu University of Technology, Jinan 250353, China; hanyan1226@126.com \\ 4 College of Life Science, Shandong Normal University, Jinan 250014, China \\ 5 School of Chemistry and Chemical Engineering, Shandong University, Jinan 250100, China \\ * Correspondence: cz17274@163.com (Z.C.); gsyang@sdu.edu.cn (G.Y.); Tel.: +86-531-66659036 (Z.C.); \\ +86-531-88364464 (G.Y.)
}

Academic Editors: Constantinos K. Zacharis and Paraskevas D. Tzanavaras Received: 15 April 2019; Accepted: 6 May 2019; Published: 9 May 2019

\begin{abstract}
Aroma plays an important role in fruit quality and varies among different fruit cultivars. In this study, a sensitive and accurate method based on headspace solid-phase microextraction (HS-SPME) coupled with comprehensive two-dimensional gas chromatography time-of-flight mass spectrometry (GC $\times$ GC-TOFMS) was developed to comprehensively compare aroma components of five pear cultivars. In total, 241 volatile compounds were identified and the predominant volatile compounds were esters (101 compounds), followed by alcohols (20 compounds) and aldehydes (28 compounds). The longyuanyangli has the highest relative concentration $(838.12 \mathrm{ng} / \mathrm{g})$, while the Packham has the lowest $(208.45 \mathrm{ng} / \mathrm{g})$. This study provides a practical method for pear aroma analysis using SPME and GCXGC-TOFMS.
\end{abstract}

Keywords: pears; HS-SPME; volatile compounds; GC×GC-TOFMS

\section{Introduction}

Pear (Pyrus spp., Rosaceae) is a popular fruit and is extensively grown in China. In 2017, based on the FAO Statistical Database, 16,527,694 tonnes of pears were produced in China taking up $68.38 \%$ of the total pear production in the world [1]. The pear cultivars mainly belong to 4 types, P. communis L., P. pyrifolia (Burm.) Nakai, P. ussuriensis Max. and P. bretschneideri Redh [2]. The P. sinkiangensis Yu. was reported as the fifth pear category.

Fruit aroma is one of the most important factors contributing to the overall flavor and consumer preference [2]. Therefore, several studies have investigated the aroma components of different pear cultivars [2-7]. The aroma compounds of pears are complicated and vary among pear cultivars. Most Occidental pears have intense aromas and juicy texture, whereas P. bretschneideri cultivars are characterized by their faint odor and crisp texture [2]. Investigation of pear aromas has focused on composition changes among pear cultivars [3-7], storage conditions influences [8-12] and postharvest treatment [11,13]. Low temperature conditioning [12], calcium treatment [13], ultralow oxygen environment $[10,11]$ and 1-methylcyclopropene (1-MCP) treatment [11] are external factors that affect pear aroma formation and emission. Volatile compounds of pears include esters, aldehydes, 
alcohols, ketones and hydrocarbons. Esters are the major volatile components in P. ussuriensis and P. communis, while in P. pyrifolia aldehydes are the dominant volatile compounds, followed by alcohols and esters [3-5]. $\mathrm{C}_{6}$ compounds $\left(\mathrm{C}_{6}\right.$ aldehydes and $\mathrm{C}_{6}$ alcohols) that were reported to be significant components in fruits [14-16] were also detected in pears [3,4].

Volatiles emitted from pear fruits have been studied by SPME and gas chromatography-mass spectrometry (GC-MS) in recent years. SPME makes great contributions to volatile compounds analysis [17]. However, investigations using GC-MS only identified a small quantity of volatile compounds. In comparison with one-dimensional gas chromatography (1D-GC), comprehensive two-dimensional gas chromatography $(\mathrm{GC} \times \mathrm{GC})$ can provide significant signal enhancement and a 5-fold to 15-fold improvement in peak capacity [18,19]. GC×GC-TOFMS has been applied to volatiles identification such as wines [20], cloud waters [21] and green teas [22], but pears are not included.

In this research, HS-SPME and GC $\times$ GC-TOFMS were used to analyse volatile compounds in five pear cultivars. Packham's Triumph, Docteur Jules Guyot, Clapp's Favorite and Starkrimson are four occidental pears, which are introduced from abroad. Longyuanyangli is a hybrid variety that has intense aroma. Therefore in this study, the aromas of five pear cultivars are comprehensively investigated.

\section{Results and Discussion}

\subsection{Optimization of the Modulation Period}

Modulation period is a parameter of crucial importance in GC $\times$ GC-TOFMS analysis. Modulator is responsible to trap and refocus the components from the 1D-column and transfer them to the 2D column for further separation [18]. The modulator makes the GC $\times$ GC possible. For aroma components analysis, the modulation period was set as $2 \mathrm{~s}, 3 \mathrm{~s}$, and $4 \mathrm{~s}$. The shorter the modulator period is, the narrower chromatography band and the higher peak capacity are obtained. As shown in Figure 1, when the modulation period was $3 \mathrm{~s}$, the retention time of 2-methylnaphthalene and 1-methylnaphthalene was $1185 \mathrm{~s}, 2.00 \mathrm{~s}$ and $1212 \mathrm{~s}, 2.08 \mathrm{~s}$, respectively. When the modulation period was $2 \mathrm{~s}$, the retention time of 2-methylnaphthalene and 1-methylnaphthalene was 1186 s, $0.00 \mathrm{~s}$ and $1214 \mathrm{~s}, 0.08 \mathrm{~s}$, respectively. The chromatographic peak of 2-methylnaphthalene was divided into two parts, which has a significant impact on the quantification process. The peak of 1-methylnaphthalene was at the very bottom in the chromatography. In order to ensure the peak shape of the volatile compounds and the accuracy of the quantitative analysis, the modulation period was set for $3 \mathrm{~s}$ with a $0.6 \mathrm{~s}$ hot pulse time.

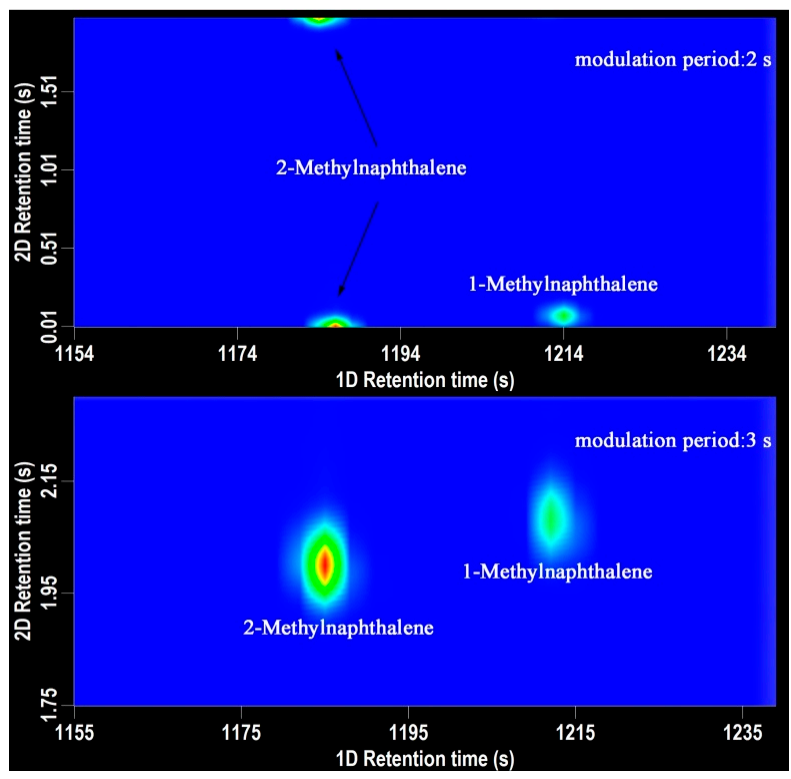

Figure 1. The 2D chromatography of 2-methylnaphthalene and 1-methylnaphthalene. (top-modulation period $2 \mathrm{~s}$, bottom-modulation period $3 \mathrm{~s}$ ). 


\subsection{SPME Fibre Selection}

Pear aromas are extremely complex and may comprise hundreds of constitutes of different physical and chemical properties. Therefore, four SPME fibres coated with different stationary phases were compared for extraction of volatile compounds. They are $100 \mu \mathrm{m}$ PDMS (nonpolar), $85 \mu \mathrm{m}$ PA (polar), $65 \mu \mathrm{m}$ PDMS/PVB (bipolar) and 50/30 $\mu \mathrm{m}$ DVB/CAR/PDMS (bipolar). The aroma components of a same yali pear (P. bertschneideri Reld) were analyzed for fibres comparison. The aroma extraction process was repeated for three times to guarantee the accuracy of the results. Figure 2 illustrates the peak numbers and the average peak areas for volatile compounds extracted from yali pear using different SPME fibres. A total of 146 and 163 volatile compounds were identified using $65 \mu \mathrm{m}$ PDMS/PVB and 50/30 $\mu \mathrm{m}$ DVB/CAR/PDMS, respectively. The fewest compounds were extracted by $85 \mu \mathrm{m}$ PA fibre. In contrast to PDMS/PVB fibre, the use of DVB/CAR/PDMS fibre can obtain higher peak areas. The peak numbers of different classes obtained using four SPME fibres were shown in Table S1. These results indicated that the $50 / 30 \mu \mathrm{m}$ DVB/CAR/PDMS fibre was the optimum for extracting volatile compounds from pears. Therefore, 50/30 $\mu \mathrm{m}$ DVB/CAR/PDMS fibre was selected for aroma extraction in this study.

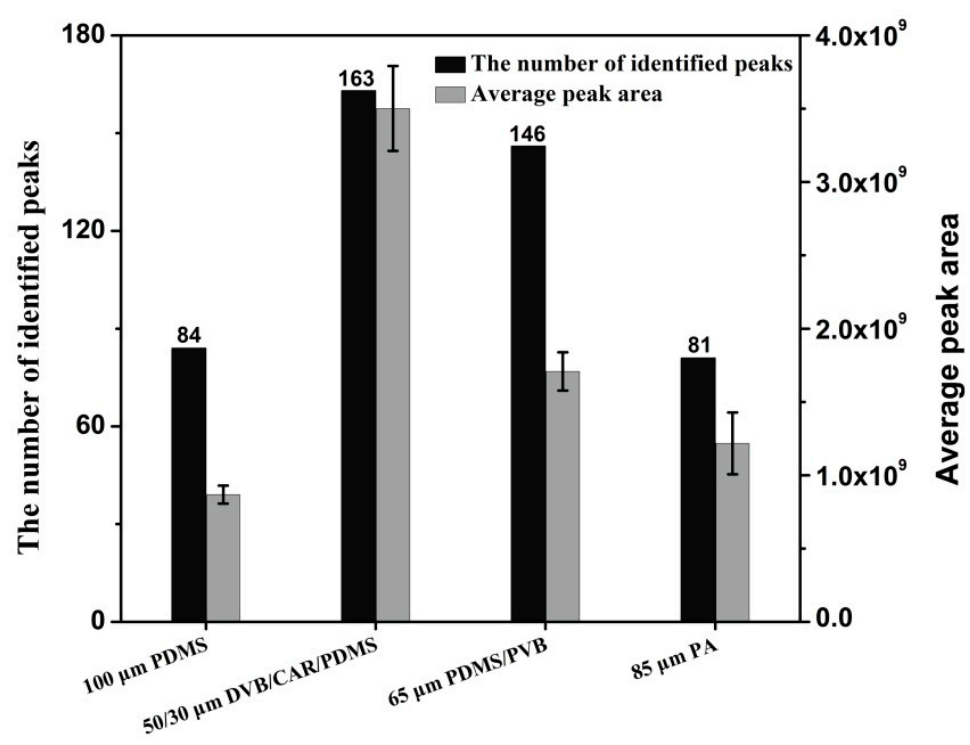

Figure 2. Comparison of aroma amounts and peak areas in pears using four different SPME fibres.

\subsection{Volatile Compounds}

The 2D chromatography of five pears obtained after HS-SPME-GC $\times$ GC-TOFMS analysis is shown in Figures S1-S5. The colour gradient reflects the intensity of the TOFMS signal from low (blue) to high (red). In this study, 241 volatile compounds were tentatively identified, including 101 esters, 30 alkenes, 12 alkanes, 19 arenes, 28 aldehydes, 8 ketones, 20 alcohols and 23 others compounds. The volatile compounds amounts show great variation in different pear cultivars and ranged from 67 compounds in Packham to 160 compounds in longyuanyangli. The number of chemical classes of each pear is shown in Figure 3. Figure 4 shows that the percentage contents of volatile compounds in pears are of large differences. Esters are the dominant aromas in pears, followed by alcohols and aldehydes. Table S2 summarizes the volatile compounds detected in five pear cultivars. In this study, the retention time of $n$-alkanes $\left(C_{5}-C_{20}\right)$ was obtained and the retention index of each volatile compound was calculated. The ChromaTOF-GC uses the Van den Dool and Kratz equation for the calculation of the retention index. The equation is:

$$
R I_{a}=\left(\frac{R T_{a}-R T_{n}}{R T_{N}-R T_{n}}\right) 100(N-n)+100 R T_{n}
$$

$R I_{a}$ : the retention index of the compound of interest; $a$ : the compound of interest; $n$ : the carbon number of the lower normal alkane; $N$ : the carbon number of the higher normal alkane; $R T$ : the retention time. 


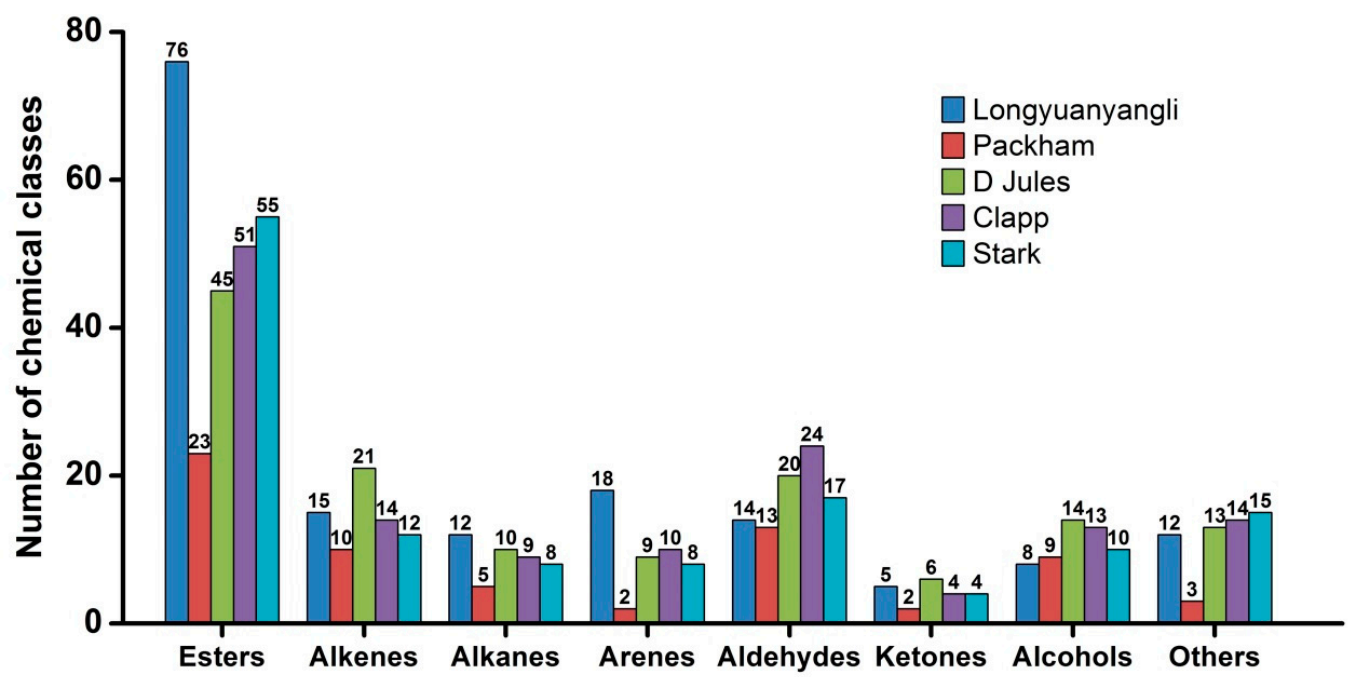

Figure 3. The number of chemical classes in pears.

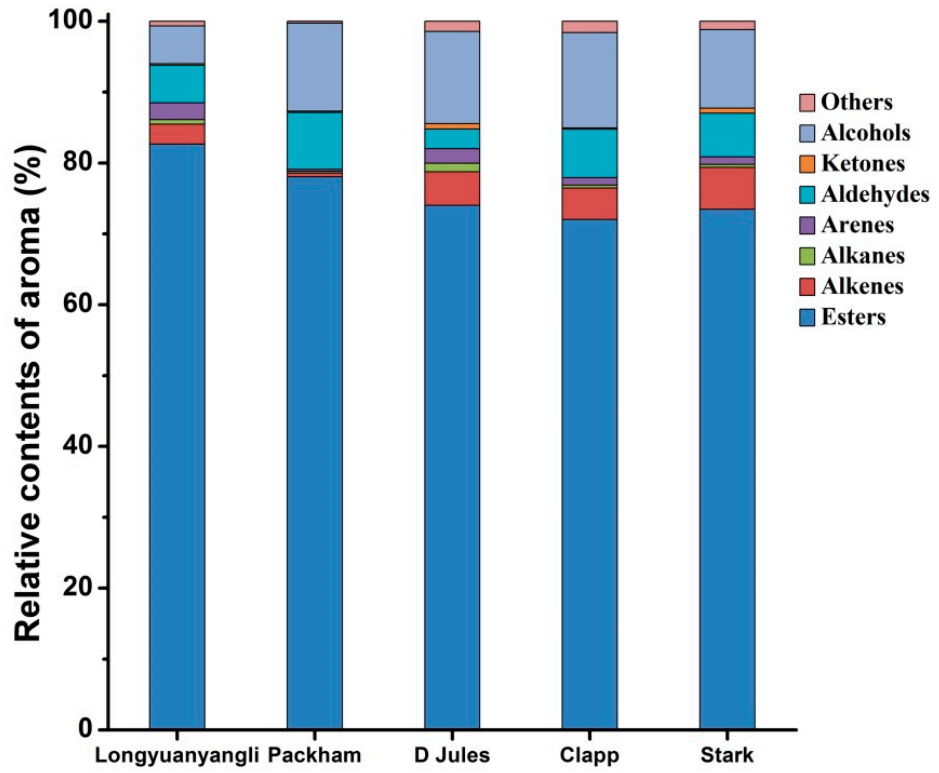

Figure 4. Relative contents of volatile compounds in five pears.

\subsubsection{Esters}

Esters are the dominant compounds in pears. A total of 76 esters were identified in longyuanyangli. Followed by Stark (55), Clapp (51), D Jules (45), and Packham, who had the fewest esters (23) (Figure 3). The longyuanyangli has the highest concentration of esters (692.72 ng/g, 82.65\%), while the Packham has the lowest (162.66 ng/g, 78.03\%) (Table S2). Acetates with high concentrations were the major ester constituents, including methyl acetate, ethyl Acetate, n-propyl acetate, butyl acetate, pentyl acetate, hexyl acetate and heptyl acetate (Table S2). Sulfur-containing compounds, ethyl 3-(methylsulfanyl)propanoate, 3-(methylthio)propyl acetate and ethyl 3-(methylthio)-(E)-2-propenoate were also detected in this study. Sulfur-containing compounds have been reported to have originated from methionine and cysteine [3] and provided the juicy, fresh aroma to many fruits [23]. Methyl $(E, Z)-2,4$-decadienoate and ethyl $(E, Z)$-2,4-decadienoate are two esters that have a pear-like smell and are major volatile compounds existed in Bartlett [10] and Beurre Bosc [3]. In this study, methyl $(E, Z)-2,4$-decadienoate and ethyl $(E, Z)-2,4$-decadienoate were also detected in longyuanyangli and Packham, but the contents (less than $0.53 \mathrm{ng} / \mathrm{g}$ ) were very low. Furthermore, long-chain aliphatic acid 
esters such as methyl tetradecanoate, methyl hexadecanoate, methyl (Z)-9-octadecenoate were also detected in this study.

\subsubsection{Alcohols}

Alcohols were the second dominant volatile compounds in the five pear cultivars (Figure 4). Alcohols account for 5.33 percent $(44.67 \mathrm{ng} / \mathrm{g})$ in longyuanyangli to 13.48 percent $(51.19 \mathrm{ng} / \mathrm{g}) \mathrm{in}$ Clapp. Ethanol was the primary alcohol compounds with the concentrations ranging from 12.34 $\mathrm{ng} / \mathrm{g}$ in Packham to $27.35 \mathrm{ng} / \mathrm{g}$ in D Jules. 1-Hexanol and trans-2-hexen-1-ol were reported in many fruits and regarded as $\mathrm{C}_{6}$ alcohols. 1-Hexanol was found in the range of $9.84 \mathrm{ng} / \mathrm{g}$ and $26.97 \mathrm{ng} / \mathrm{g}$, but trans-2-hexen-1-ol was only detected in Packham in the concentration of $0.50 \mathrm{ng} / \mathrm{g}$ (Table S2). In addition, 1-butanol and 1-heptanol are straight-chain alcohols, which existed in all pears. Linalool, which possesses a floral and citrus-like aroma [22,24], was identified in D Jules cultivar for the first time. Citronellol was identified in D Jules, Clapp and Stark with low concentration.

\subsubsection{Aldehydes and Ketones}

The largest number of aldehydes compounds (24) was detected in Clapp, and Packham contained the fewest aldehydes (13) (Figure 3). The concentrations of aldehydic compounds were relatively low in all pears other than acetaldehyde, hexanal and (E)-2-hexenal. Acetaldehyde was detected in high concentrations ranged from $4.81 \mathrm{ng} / \mathrm{g}$ in D Jules to $23.71 \mathrm{ng} / \mathrm{g}$ in longyuanyangli. $\mathrm{C}_{6}$ compounds $\left(\mathrm{C}_{6}\right.$ aldehydes and $\mathrm{C}_{6}$ alcohols) are regarded as green leaf volatiles and contribute to the herbaceous odour in fruits [14-16]. In this study, hexanal, (E)-2-hexenal and 1-hexanol are dominant $\mathrm{C}_{6}$ compounds. The concentration of hexanal ranged from $2.07 \mathrm{ng} / \mathrm{g}$ in D Jules to $12.46 \mathrm{ng} / \mathrm{g}$ in longyuanyangli and the $(E)$-2-hexenal concentration changed from $1.60 \mathrm{ng} / \mathrm{g}$ in D Jules to $6.27 \mathrm{ng} / \mathrm{g}$ in longyuanyangli. In addition, benzaldehyde was detected in all pears. Benzaldehyde has an almond-like smell and has been previously isolated from green teas [22], lychee [24], and apricot [16]. Figure 4 shows that small proportion ketones were detected. In total, eight ketones were found, but 6-methyl-5-heptene-2-one was the only ketone that presented in all pears. It has been reported that 6-methyl-5-heptene-2-one was present in higher amount in the peel compared to the flesh and was a degradation product of lycopene [16] or $\alpha$-farnesene [25,26]. In addition, 6-methyl-5-heptene-2-one possesses fatty, green, citrus odour [27] and is a common ketone existed in many fruits [16,24,28,29].

\subsubsection{Hydrocarbons}

Although 12 alkanes were identified, the relative contents were very low. A series of $n$-alkanes $\left(C_{13}-C_{16}\right)$ existed in all five pears. Alkenes account for $0.56-5.88 \%$ in total volatile compounds (Figure 4). A total of 30 alkenes were detected, comprising aliphatic alkenes (5), aromatic alkenes (6) and terpenes (19). Styrene was previously identified in Chinese white pear [5]. In addition to styrene, aromatic alkenes identified in this study comprise 1-propenylbenzene, 1-ethenyl-3-ethylbenzene, 1-ethenyl-4-ethylbenzene, 1,4-dethenyl benzene, 1,3-diethenylbenzene. Terpenes which play important role in fruit flavors have been identified in pears even if their contents were much lower than other compounds. Among these terpenes, $\beta$-myrcene (Grassy, piney), ( $Z$ )- $\beta$-ocimene (floral, citrusy) and limonene (citrusy) are three monoterpenes [30]. Furthermore, $\beta$-myrcene has been previously identified in mango [31], apricot [16] and lychee [24]. In this study, four isomers of farnesene were detected for the first time, including $(E)$ - $\beta$-farnesene, $(Z, E)$ - $\alpha$-farnesene, $\alpha$-farnesene and $(Z, Z)$ - $\alpha$-farnesene. $\alpha$-farnesene is the only alkenes found in five pear cultivars and accounted for the highest proportion in alkenes. (E)- $\beta$-farnesene, $(Z, E)$ - $\alpha$-farnesene and $(Z, Z)-\alpha$-farnesene were also identified in four pear cultivars other than Packham. (E)- $\gamma$-bisabolene, $(Z)-\gamma$-bisabolene and $\alpha$-humulene are major volatile compounds in carrots [32,33]. It is the first time that $(E)-\gamma$-bisabolene and $(Z)-\gamma$-bisabolene were found in pears. The two isomers existed in all pears apart from Packham. The $\alpha$-humulene contributing to the woody smell [32] was identified in Packham and Clapp. Other terpenes such as $\alpha$-cubenene, copaene, $\alpha$-muurolene, $(+)$ - $\delta$-cadinene, cis-calamenene, $\alpha$-calacorene also play important role in pear aroma. 
In contrast to other chemical classes of volatiles, arenes are minor components of total volatiles. A total of 19 arenes were identified in this study. In addition to benzene and benzene homologous compounds, polycyclic aromatic hydrocarbon 2-methylnaphthalene, 1-methylnaphthalene, naphthalene were also found (Table S2).

\subsubsection{Others}

Pears have high concentrations of esters, alcohols, aldehydes and alkenes which are of great significance on fruit aroma. Nevertheless, other compounds (23 compounds) such as benzonitrile, 2-pentylfuran, estragole and sesquirosefuran also contribute to the overall flavor of pears and account for $0.26-1.53 \%$ of the total volatiles. Among these volatiles, three volatile acids were identified, including acetic acid, thioacetic acid and (E)-3-octenoic acid. Eucalyptol, which is characterized by a fresh, camphoraceous, cool odour [34] was detected in longyuanyangli in the concentration of $0.89 \mathrm{ng} / \mathrm{g}$. Sesquirosefuran, a natural constituent existed in essential oils [35,36], was detected in D Jules, Clapp and Stark. Previous study has shown the existence of estragole in Pyrus ussuriensis cultivars [4], but its isomers anethole and (Z)-1-methoxy-4-(prop-1-en-1-yl)benzene were also identified in this study. Additionally, 2-pentylfuran was found in five pear cultivars and was perceived as having a fruity, green, earthy and vegetable-like smell [22]. Benzonitrile which was identified in Pyrus ussuriensis cultivars [4] was also indentified in longyuanyangli and D Jules. Other compounds such as phenol, $(Z)$-rose oxide and $(E)$-rose oxide were also detected in this study. Various aroma components and concentration difference determine the overall flavor properties of pears.

\subsection{Cluster Analysis (CA)}

The cluster analysis based on concentrations of identified volatile compounds was performed using the SPSS Statistical 19.0 software. The dendrogram (Figure 5) shows that two main groups are distinguished. Longyuanyangli, which has the maximum aroma numbers and the highest concentrations, is separated from other pear cultivars. Packham, D Jules, Clapp and Stark constitute the second group. They are four Occidental pears, which are introduced from abroad. Figure 5 shows that the D Jules and Stark have the slightest differences compared with other cultivars. Many factors affect the volatile compounds composition of the fruits. In this study, the volatile compositions of pears were found to be considerably different.

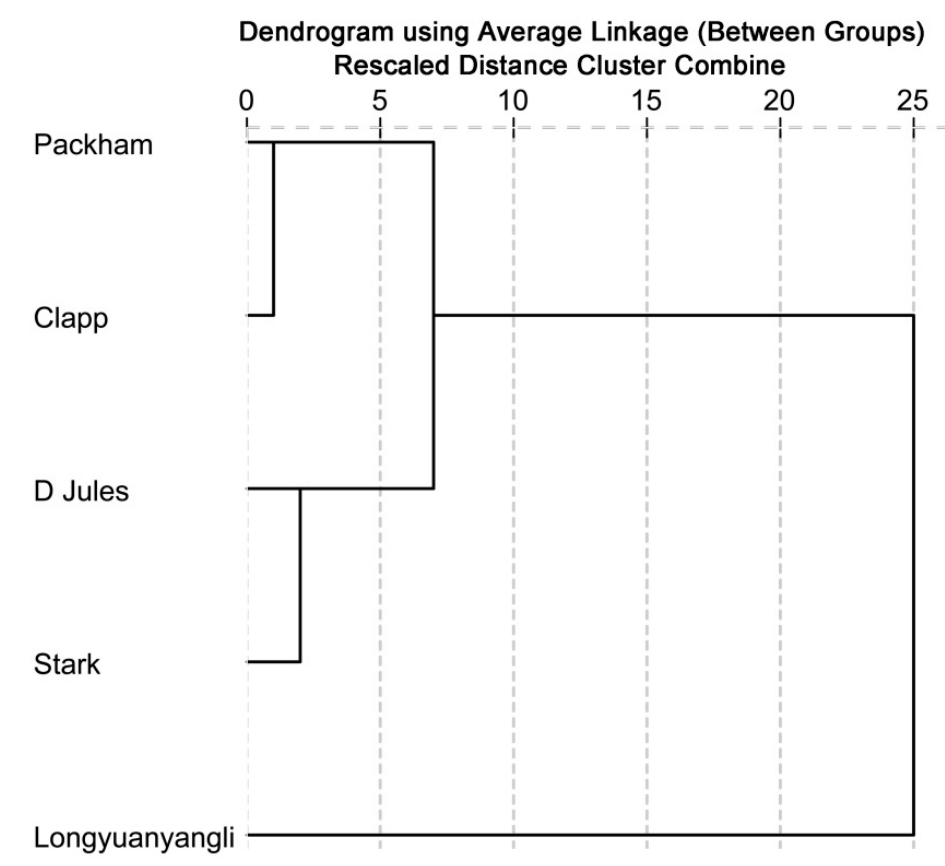

Figure 5. Dendrogram obtained from cluster analysis based on the identified volatile compounds. 


\section{Materials and Methods}

\subsection{Materials}

Five pear cultivars were prepared for analysis. The detailed information of the pears is shown in Table 1. The conventional indicators such as growing period, external morphology and skin color were used to judge the maturity of each cultivar. All fruits were stored at $1{ }^{\circ} \mathrm{C}$ before experiments. For each cultivar in this study, after-ripening process was necessary to enhance the flavor and taste. Samples were placed at room temperature before experiments (approximately five days). The 4 SPME fibres (100 $\mu \mathrm{m}$ PDMS, $85 \mu \mathrm{m}$ PA, $65 \mu \mathrm{m}$ PDMS/PVB and 50/30 $\mu \mathrm{m}$ DVB/CAR/PDMS) were supplied by Supelco (Bellefonte, PA, USA). The length of the fibre coating is $1 \mathrm{~cm}$. The internal standard 2-nonanone (>99\%) was obtained from Dr. Ehrensorfer (Germany).

Table 1. The cultivars, abbreviation, producing area and sampling time of 5 pears.

\begin{tabular}{cccc}
\hline Pear Cultivars & Abbreviation & Producing Area & Sampling Time \\
\hline Longyuanyangli & longyuanyangli & Qiqihaer city of Heilongjiang province & 07 September 2018 \\
Packham's Triumph & Packham & Weihai city of Shandong Province & 27 September 2018 \\
Docteur Jules Guyot & D Jules & Yantai city of Shandong Province & 01 August 2018 \\
Clapp's Favorite & Clapp & Yantai city of Shandong Province & 07 August 2018 \\
Starkrimson & Stark & Yantai city of Shandong Province & 01 August 2018 \\
\hline
\end{tabular}

\subsection{Volatiles Extraction}

HS-SPME was used for volatile compounds extraction. A 50/30 $\mu \mathrm{m}$ DVB/CAR/PDMS SPME fibre was used in this study. Fibres were activated according to the conditioning guidelines before the first use. The core of each pear was removed, while the peel was reserved. The skin and flesh of each pear was cut into cubes $(0.5 \mathrm{~cm} \times 0.5 \mathrm{~cm} \times 0.5 \mathrm{~cm})$. For each extraction, $6.0 \mathrm{~g}$ of sample were placed into a 15-mL screw-cap vial. Prior to sealing of the vials, $5 \mu \mathrm{L}$ of $10 \mu \mathrm{g} / \mathrm{mL} 2$-nonanone was added as internal standard, and was standing for $10 \mathrm{~min}$. Then each vial was placed in a constant-temperature controller at $40^{\circ} \mathrm{C}$ for $40 \mathrm{~min}$. Finally, the SPME fibre was immediately inserted into the GC injector for desorption at $270{ }^{\circ} \mathrm{C}$ for $2 \mathrm{~min}$ in the split mode of 10:1.

\subsection{GC $\times G C-T O F M S$ Conditions}

The volatile compounds analysis was performed with an Agilent 7890B gas chromatography equipped with a Pegasus 4D-C time-of-flight mass spectrometric detector. A Rxi-5MS column (30 $\mathrm{m} \times 250 \mu \mathrm{m} \times 0.25 \mu \mathrm{m})$ was used as the first-dimension (1D) column, and a Rxi-17Sil MS column $(2 \mathrm{~m} \times 250 \mu \mathrm{m} \times 0.25 \mu \mathrm{m})$ was used as the second-dimension (2D) column. Helium was used as the carrier gas at a constant flow of $1.4 \mathrm{~mL} / \mathrm{min}$. The front inlet and the transfer line temperature were $270{ }^{\circ} \mathrm{C}$ and $280^{\circ} \mathrm{C}$, respectively. The oven temperature programme conditions were as follows: initial temperature was $40^{\circ} \mathrm{C}$ for $2 \mathrm{~min}$, rose at $5{ }^{\circ} \mathrm{C} / \mathrm{min}$ up to $200{ }^{\circ} \mathrm{C}$, then ramped to $280^{\circ} \mathrm{C}$ at $20^{\circ} \mathrm{C} / \mathrm{min}$ and hold for $2 \mathrm{~min}$. The secondary oven temperature was kept at $5^{\circ} \mathrm{C}$ above the GC oven temperature throughout the chromatographic run. The modulator temperature was offset by $15^{\circ} \mathrm{C}$ in relative to the secondary oven temperature. The modulation period was set for $3 \mathrm{~s}$ with a $0.6 \mathrm{~s}$ hot pulse time.

The MS parameters were as follows: acquisition delay $60 \mathrm{~s}$, acquisition rate 100 (spectra/s), the acquisition voltage $1450 \mathrm{~V}$, electron energy $-70 \mathrm{~V}$, ion source $250{ }^{\circ} \mathrm{C}$. Mass spectra were acquired in the $m / z$ range $35-550 \mathrm{amu}$.

\subsection{Data Processing and Statistical Analysis}

LECO ChromaTOF Version 4.73.3.0 software (Leco Corporation, St. Joseph, MO, USA) was used for instrument control, data acquisition and processing. Each chromatograph peak was compared to National Institute of Standards and Technology (NIST2017) library and the minimum similarity is 800. 
The area of the base peak was used for quantification. The quantitative analysis for aroma components was carried out by internal standard method using 2-nonanone as an internal standard. Therefore, the concentration of each volatile compound was normalized to that of 2-nonanone. The formula for volatile compounds quantification is as follows:

$$
C_{a}=\frac{\frac{P A_{a}}{P A_{i s}} \times C_{i s} \times 5 \mu L}{m}
$$

$C_{a}$ : the concentration of aroma components $(\mathrm{ng} / \mathrm{g}) ; P A_{a}$ : peak area of aroma components; $P A_{i s}$ : peak area of internal standard; $C_{i s}$ : the concentration of internal standard $(\mathrm{g} / \mathrm{mL}) ; m$ : mass of sample $(\mathrm{g})$. The concentration of the 2-nonanone was $10 \mu \mathrm{g} / \mathrm{mL}$ and the mass of sample was $6.0 \mathrm{~g}$. Data are means \pm SD of three replications. Cluster analysis (CA) was performed using the SPSS Statistical 19.0.

\section{Conclusions}

In conclusion, the combination of SPME and GC $\times$ GC-TOFMS has improved the analysis of pear volatile compounds. The 50/30 $\mu \mathrm{m}$ DVB/CAR/PDMS SPME fibre exhibited obvious advantages for volatile compounds extraction. A total of 241 compounds were identified in five pear cultivars, which are primarily esters, alcohols, aldehydes and alkenes. Volatile compounds such as sesquirosefuran and anethole are reported for the first time in pears. Evaluation of aromas at the germplasm level will facilitate breeding efforts and improve sensory quality of fruits. This research will contribute to further studies related to volatile compounds analysis.

Supplementary Materials: The following are available online, Figure S1: 2D chromatogram (total ion chromatography) of Longyuanyangli, Figure S2: 2D chromatogram (total ion chromatography) of Packham, Figure S3: 2D chromatogram (total ion chromatography) of D Jules, Figure S4: 2D chromatogram (total ion chromatography) of Clapp, Figure S5: 2D chromatogram (total ion chromatography) of Stark, Table S1: The peak numbers of different classes obtained using 4 SPME fibres, Table S2: Concentrations of volatile compounds in pear cultivars.

Author Contributions: C.W. and W.Z. conceived and designed the experiments; C.W. performed the experiments; C.W. and Y.W. analyzed the data; R.D. and L.F. contributed materials; H.L. and J.M. and C.G. helped the use of the GC $\times$ GC-TOFMS; C.W. wrote the paper; Z.C. and G.Y. helped to revise the manuscript. All authors read and approved the final manuscript.

Funding: This research was supported by National Pear Industry Technology System (CARS-28-23) and Agricultural Science and Technology Innovation Project of Shandong Academy of Agricultural Sciences (CXGC2017A03).

Conflicts of Interest: The authors declare no conflict of interest.

\section{References}

1. FAO Statistical Database. Available online: http://www.fao.org/home/en/ (accessed on 20 December 2018).

2. Rapparini, F.; Predieris, S. Pear fruit volatiles. Hort. Rev. 2003, 28, 237-324.

3. Chen, Y.Y.; Yin, H.; Wu, X.; Shi, X.J.; Qi, K.J.; Zhang, S.L. Comparative analysis of the volatile organic compounds in mature fruits of 12 Occidental pear (Pyrus communis L.) cultivars. Sci. Hortic. 2018, 240, $239-248$. [CrossRef]

4. Qin, G.H.; Tao, S.T.; Cao, Y.F.; Wu, J.Y.; Zhang, H.P.; Huang, W.J.; Zhang, S.L. Evaluation of the volatile profile of 33 Pyrus ussuriensis cultivars by HS-SPME with GC-MS. Food Chem. 2012, 134, 2367-2382. [CrossRef]

5. Yi, X.K.; Liu, G.F.; Rana, M.M.; Zhu, L.W.; Jiang, S.L.; Huang, Y.F.; Lu, W.M.; Wei, S. Volatile profiling of two pear genotypes with different potential for white pear aroma improvement. Sci. Hortic. 2016, 209, 221-228. [CrossRef]

6. Takeoka, G.R.; Buttery, R.G.; Flath, R.A. Volatile constituents of asian pear (Pyrus serotina). J. Agric. Food chem. 1992, 40, 1925-1929. [CrossRef]

7. Katayama, H.; Ohe, M.; Sugawara, E. Diversity of odor-active compounds from local cultivars and wild accessions of Iwateyamanashi (Pyrus ussuriensis var. aromatica) revealed by aroma extract dilution analysis (AEDA). Breed. Sci. 2013, 63, 86-95. [CrossRef] [PubMed] 
8. Chen, J.L.; Wu, J.H.; Wang, Q.; Deng, H.; Hu, X.S. Changes in the volatile compounds and chemical and physical properties of Kuerle fragrant pear (Pyrus serotina Reld) during Storage. J. Agric. Food Chem. 2006, 54, 8842-8847. [CrossRef] [PubMed]

9. Chen, J.L.; Yan, S.; Feng, Z.; Xiao, L.; Hu, X.S. Changes in the volatile compounds and chemical and physical properties of Yali pear (Pyrus bertschneideri Reld) during storage. Food Chem. 2006, 97, 248-255. [CrossRef]

10. Zlatić, E.; Zadnik, V.; Fellman, J.; Demšar, L.; Hribar, J.; Čejić, Ž.; Vidrih, R. Comparative analysis of aroma compounds in 'Bartlett' pear in relation to harvest date, storage conditions, and shelf-life. Postharvest Biol. Technol. 2016, 117, 71-80. [CrossRef]

11. Hendges, M.V.; Neuwald, D.A.; Steffens, C.A.; Vidrih, R.; Zlatić, E.; do Amarante, C.V.T. 1-MCP and storage conditions on the ripening and production of aromatic compounds in Conference and Alexander Lucas pears harvested at different maturity stages. Postharvest Biol. Technol. 2018, 146, 18-25. [CrossRef]

12. Zhou, X.; Dong, L.; Li, R.; Zhou, Q.; Wang, J.W.; Ji, S.J. Low temperature conditioning prevents loss of aroma-related esters from 'Nanguo' pears during ripening at room temperature. Postharvest Biol. Technol. 2015, 100, 23-32. [CrossRef]

13. Wei, S.W.; Qin, G.H.; Zhang, H.P.; Tao, S.T.; Wu, J.; Wang, S.M.; Zhang, S.L. Calcium treatments promote the aroma volatiles emission of pear (Pyrus ussuriensis 'Nanguoli') fruit during post-harvest ripening process. Sci. Hortic. 2017, 215, 102-111. [CrossRef]

14. Wang, Y.J.; Yang, C.X.; Li, S.H.; Yang, L.; Wang, Y.N.; Zhao, J.B.; Jiang, Q. Volatile characteristics of 50 peaches and nectarines evaluated by HP-SPME with GC-MS. Food Chem. 2009, 116, 356-364. [CrossRef]

15. Yang, C.X.; Wang, Y.J.; Liang, Z.C.; Fan, P.G.; Wu, B.H.; Yang, L.; Wang, Y.N.; Li, S.H. Volatiles of grape berries evaluated at the germplasm level by headspace-SPME with GC-MS. Food Chem. 2009, 114, 1106-1114. [CrossRef]

16. Gokbulut, I.; Karabulut, I. SPME-GC-MS detection of volatile compounds in apricot varieties. Food Chem. 2012, 132, 1098-1102. [CrossRef]

17. Xu, C.H.; Chen, G.S.; Xiong, Z.H.; Fan, Y.X.; Wang, X.C.; Liu, Y. Applications of solid-phase microextraction in food analysis. TrAC-Trends Anal. Chem. 2016, 80, 12-29. [CrossRef]

18. Murray, J.A. Qualitative and quantitative approaches in comprehensive two-dimensional gas chromatography. J. Chromatogr. A 2012, 1261, 58-68. [CrossRef]

19. Freye, C.E.; Bahaghighat, H.D.; Synovec, R.E. Comprehensive two-dimensional gas chromatography using partial modulation via a pulsed flow valve with a short modulation period. Talanta 2018, 177, 142-149. [CrossRef]

20. Welke, J.E.; Zanus, M.; Lazzarotto, M.; Pulgati, F.H.; Zini, C.A. Main differences between volatiles of sparkling and base wines accessed through comprehensive two dimensional gas chromatography with time-of-flight mass spectrometric detection and chemometric tools. Food Chem. 2014, 164, 427-437.

21. Lebedev, A.T.; Polyakova, O.V.; Mazur, D.M.; Artaev, V.B.; Canet, I.; Lallement, A.; Vaitilingom, M.; Deguillaume, L.; Delort, A.M. Detection of semi-volatile compounds in cloud waters by GC $\times$ GC-TOF-MS. Evidence of phenols and phthalates as priority pollutants. Environ. Pollut. 2018, 241, 616-625. [CrossRef]

22. Zhu, Y.; Lv, H.P.; Shao, C.Y.; Kang, S.; Zhang, Y.; Guo, L.; Dai, W.D.; Tan, J.F.; Peng, Q.H.; Lin, Z. Identification of key odorants responsible for chestnut-like aroma quality of green teas. Food Res. Int. 2018, 108, 74-82. [CrossRef]

23. Cannon, R.J.; Ho, C.T. Volatile sulfur compounds in tropical fruits. J. Food Drug Anal. 2018, 26, 445-468. [CrossRef]

24. Feng, S.; Huang, M.Y.; Crane, J.H.; Wang, Y. Characterization of key aroma-active compounds in lychee (Litchi chinensis Sonn.). J. Food Drug Anal. 2018, 26, 497-503. [CrossRef]

25. Mir, N.A.; Beaudry, R. Effect of superficial scald suppression by diphenylamine application on volatile evolution by stored cortland apple fruit. J. Agric. Food Chem. 1999, 47, 7-11. [CrossRef]

26. Hui, W.; Niu, J.P.; Xu, X.Y.; Guan, J.P. Evidence supporting the involvement of MHO in the formation of superficial scald in 'Dangshansuli' pears. Postharvest Biol. Technol. 2016, 121, 43-50. [CrossRef]

27. The Good Scents Company Information System. Available online: http://www.thegoodscentscompany.com/ index.html (accessed on 5 January 2019).

28. Cheng, H.; Chen, J.L.; Li, X.; Pan, J.X.; Xue, S.J.; Liu, D.H.; Ye, X.Q. Differentiation of the volatile profiles of Chinese bayberry cultivars during storage by HS-SPME-GC/MS combined with principal component analysis. Postharvest Biol. Technol. 2015, 100, 59-72. [CrossRef] 
29. Mannucci, A.; Serra, A.; Remorini, D.; Castagna, A.; Mele, M.; Scartazza, A.; Ranieri, A. Aroma profile of Fuji apples treated with gelatin edible coating during their storage. LWT Food Sci. Technol. 2017, 85, 28-36. [CrossRef]

30. Amanpour, A.; Guclu, G.; Kelebek, H.; Selli, S. Characterization of key aroma compounds in fresh and roasted terebinth fruits using aroma extract dilution analysis and GC-MS-Olfactometry. Microchem. J. 2019, 145, 96-104. [CrossRef]

31. Zakaria, S.R.; Saim, N.; Osman, R.; Abdul Haiyee, Z.; Juahir, H. Combination of sensory, chromatographic, and chemometrics analysis of volatile organic compounds for the discrimination of authentic and unauthentic harumanis mangoes. Molecules 2018, 23, 2365. [CrossRef]

32. Kjeldsen, F.; Christensen, L.P.; Edelenbos, M. Changes in volatile compounds of carrots (Daucus carota L.) during refrigerated and frozen storage. J. Agric. Food Chem. 2003, 51, 5400-5407. [CrossRef]

33. Kjeldsen, F.; Christensen, L.P.; Edelenbos, M. Quantitative analysis of aroma compounds in carrot (Daucus carota L.) cultivars by capillary gas chromatography using large-volume injection technique. J. Agric. Food Chem. 2001, 49, 4342-4348. [CrossRef] [PubMed]

34. Fariña, L.; Boido, E.; Carrau, F.; Versini, G.; Dellacassa, E. Terpene compounds as possible precursors of 1,8-cineole in red grapes and wines. J. Agric. Food Chem. 2005, 53, 1633-1636. [CrossRef] [PubMed]

35. Heuskin, S.; Godin, B.; Leroy, P.; Capella, Q.; Wathelet, J.P.; Verheggen, F.; Haubruge, E.; Lognay, G. Fast gas chromatography characterisation of purified semiochemicals from essential oils of Matricaria chamomilla $\mathrm{L}$. (Asteraceae) and Nepeta cataria L. (Lamiaceae). J. Chromatogr. A 2009, 1216, 2768-2775. [CrossRef] [PubMed]

36. Jalali-Heravi, M.; Parastar, H.; Sereshti, H. Development of a method for analysis of Iranian damask rose oil: combination of gas chromatography-mass spectrometry with Chemometric techniques. Anal. Chim. Acta 2008, 623, 11-21. [CrossRef] [PubMed]

Sample Availability: Not available.

(C) 2019 by the authors. Licensee MDPI, Basel, Switzerland. This article is an open access article distributed under the terms and conditions of the Creative Commons Attribution (CC BY) license (http://creativecommons.org/licenses/by/4.0/). 